\title{
La geologia que ens envolta: contextualitzem
}

\author{
Silvia Leiva Hevia (sleiva3@xtec.cat) Institut Lliçà d'Amunt
}

Per aconseguir que la Geologia resulti més atraient $i$ entenedora per l'alumnat de primer d'ESO, en aquesta seqüència didàctica es realitzen activitats amb diferents orientacions metodològiques: construcció d'una maqueta de modelatge càrstic, sortida de camp a Sant Miquel del Fai per poder treballar "in situ" els coneixements adquirits a l'aula i creació d'un itinerari geològic urbà per la població de Lliçà d'Amunt. Els alumnes fan una descoberta de l'entorn proper, descobreixen l'ús dels recursos geològics a la seva població i treballen l'observació i respecte per la natura.

Paraules clau: sortida geològica, maqueta, roques sedimentàries, riu, modelat càrstic, recorregut urbà, entorn, observació natura.

To make Geology more attractive and understandable for ESO students, they carry out activities with different methodological guidelines: construction of a model of the Karst modeling, exit of the field in Sant Miquel del Fai to be able to work "in situ" the knowledge acquired in the classroom and creation of an urban geological itinerary for the population of Lliçà d'Amunt. Students make a discovery of the nearby environment, discover the use of geological resources in their population and work on observation and respect for nature.

Paraules clau: geological excursion, scale model, sedimentary rocks, river, karstic modeling, urban route, environment, nature observation.

\section{FINALITAT I ORIENTACIONS}

Segons el currículum que apareix a la LOMCE a primer de l'ESO a ciències naturals s'han de treballar els conceptes de Biologia i Geologia. La Geologia no es tornarà a veure fins l'optativa a $4 \mathrm{t}$ d'ESO, per tant, és important que l'alumnat assoleixi uns coneixements bàsics a $1 \mathrm{r}$ de l'ESO i que ho treballem d'una forma atraient i motivadora.

Aquesta experiència l'he realitzat durant el segon trimestre del curs 2016/17 amb els alumnes de primer de l'ESO.

Desprès de treballar a l'aula i al laboratori l'origen i la classificació de les roques aquest curs hem afegit una activitat prèvia a la sortida de geologia que ha tingut molt èxit: la realització de maquetes de modelat càrstic que hem exposat al centre.

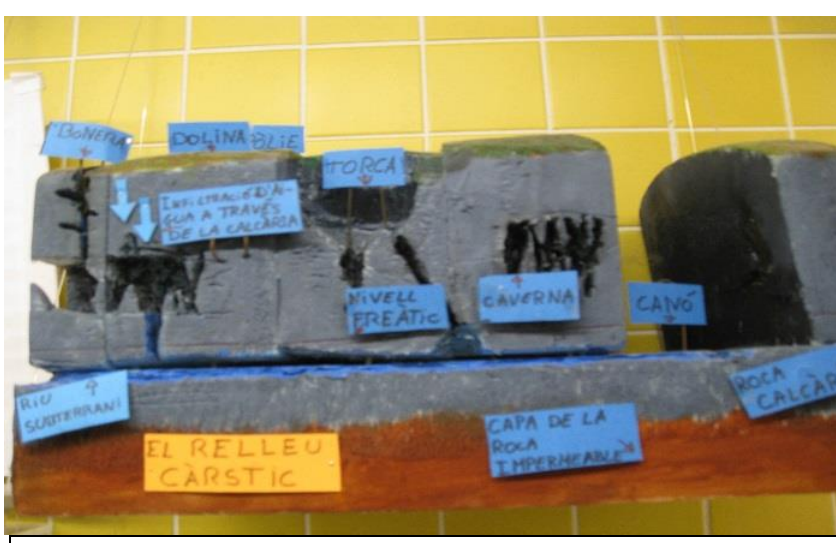

Figura 1. Maqueta de modelatge càrstic exposada al centre.

Les pautes $\mathrm{i}$ indicacions per realitzar la maqueta les he facilitat via el meu Moodle. Les maquetes les han construït de forma individual en horari extraescolar i fent servir tot tipus de materials: fang, cartró, 
suro, porexpan, plastilina...inclús hem tingut una creada amb impressora en 3D.

Aquesta activitat ha servit per preparar i observar les diferents formacions geològiques que trobaríem durant el recorregut geològic a Sant Miquel del Fai.

\section{L'ACTIVITAT}

Aquesta sortida/caminada és una activitat ja tradicional al INS Lliçà d'Amunt que constitueix un atractiu recurs didàctic. Portem més de 15 anys realitzant-la, però el curs vinent l'espaï estarà tancat ja que el passat dia 23 de juny, la Diputació de Barcelona l'ha comprat i vol fer reformes.

L'entorn proper de Lliçà d'Amunt està dominat pels cingles de Bertí. Aquestes cingleres formades per materials d'origen sedimentari formen penya-segats que tenen un important valor ecològic i paisatgístic i són de fàcil comprensió per l'alumnat.

L'itinerari escollit és el camí rural que uneix el poble de Riells del Fai amb l'antic monestir de Sant Miquel del Fai (amb un desnivell d'uns $300 \mathrm{~m}$ i una distància d'uns $7 \mathrm{~km}$ ). S'interna per la vall del Tenes dominada per les cingleres del Perer i les costes de Sant Miquel $\mathrm{i}$ al fons hi trobem el riu Tenes que ha tingut un paper molt important en la formació de la vall. Amb una mica de sort, si la pluviometria ha acompanyat prèviament, podrem apreciar un salt d'aigua (que dóna nom al territori: "fall" o "fai", segons la pronúncia local) al arribar al santuari de Sant Miquel del Fai.

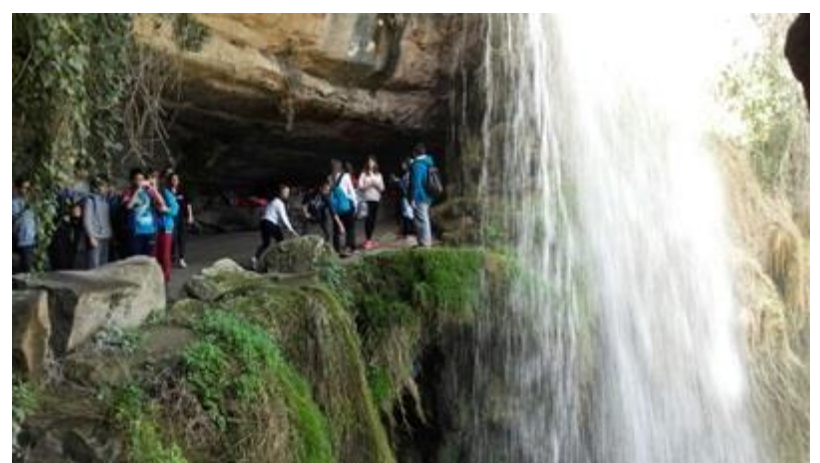

Figura 2. Cascada Sant Miquel del Fai

Durant la caminada de tot un matí fem diverses aturades per estudiar gresos, argiles i conglomerats vermells, i per sobre gresos, lutites i carbonats blancs. Anem omplint el dossier de la sortida i observant la mida de l'aflorament, l'ambient de formació, la presència de fòssils, la reacció amb $\mathrm{HCl}$, l'evolució de la composició dels clasts dels conglomerats en ascendir en la sèrie, i les anem dibuixant al dossier que cada parella d'alumnes porta.

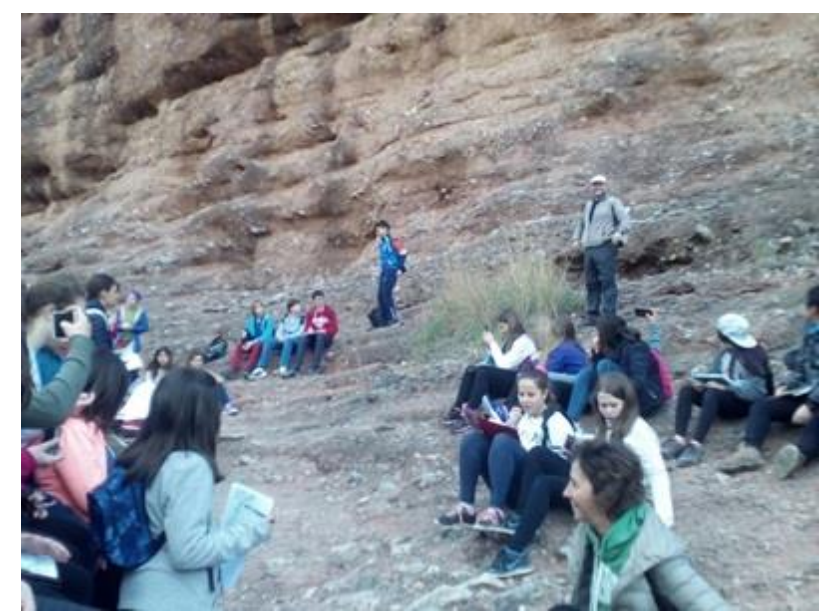

Figura 3. Aturada per estudiar els afloraments de l'itinerari

Un cop arribem al santuari de Sant Miquel del Fai, que es troba sota la balma de la cinglera, en un estret replà penjat a mitja vessant dels cingles de Bertí, observem les estalactites i estalagmites, les banderes, els travertins en formació i les balmes excavades per l'erosió a causa de les diferències de dureses de les roques. També visitem les dues coves: la cova de Sant Miquel, originada com a resultat del creixement d'una cortina de travertí al davant d'una balma, amb el salt d'aigua, i la cova de les Tosques, també anomenada cova del Bon Pastor o cova Sant Martí, formada per dissolució de la massa de travertí a la qual hem d'entrar amb casc de protecció. Dins del recinte hi ha cartells informatius que faciliten la visita.

Per últim, finalitzem aquesta unitat didàctica amb la creació d'un itinerari geològic per la població de Lliçà d'Amunt. És un dels municipis més dispersos $\mathrm{i}$ fragmentats del Vallès, ja que per tot arreu hi ha urbanitzacions que cobreixen els turons, petites barriades i infraestructures que s'escampen per tot el pla i que moltes vegades són desconegudes pels propis alumnes. Per tant, amb aquesta activitat, afavorirem el coneixement del seu municipi.

Aquesta darrera activitat I'hem incorporat nova aquest curs i ha consistit en treballar en petits grups (3-4 alumnes) per realitzar un PowerPoint i fer la presentació oral a la classe. Les indicacions de com ferho estaven al Moddle per poder consultar-ho: un mínim de 8 parades/roques dels nostres carrers, indi- 
cant la seva ubicació en un plànol (fent servir el Google Earth), el nom i tipus de roques, classificació i funció, tot indicant el recorregut pel poble.

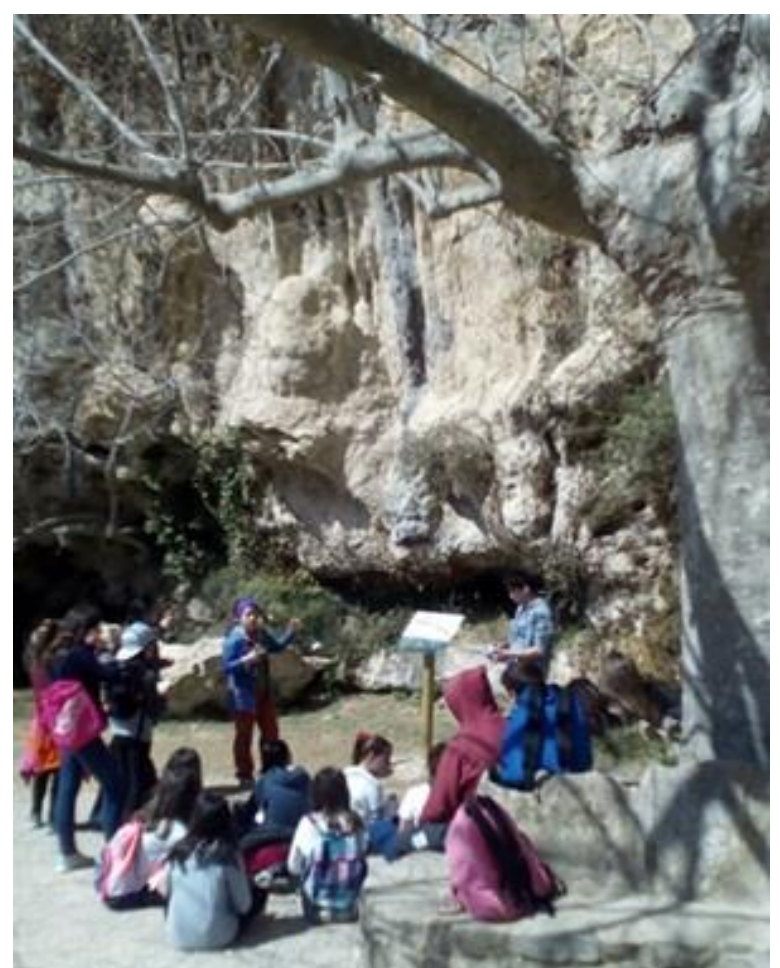

Figura 4. Explicant com es formen els travertins

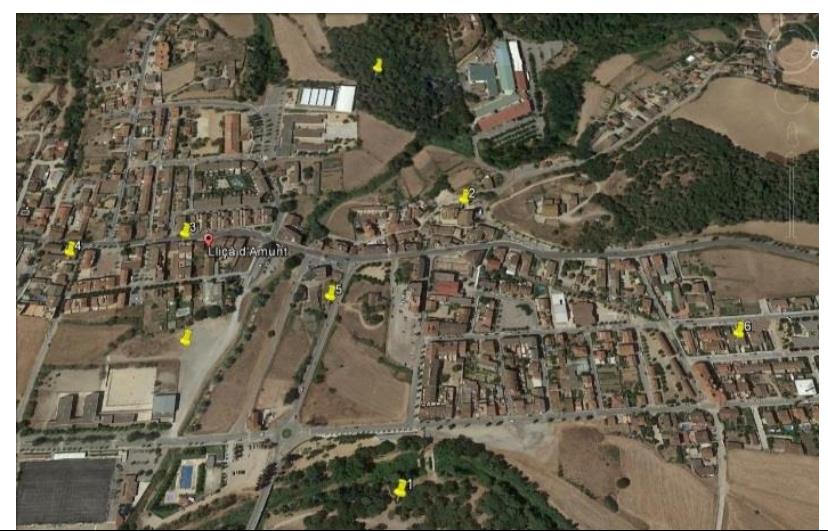

Figura 5. Exemple del treball "itinerari geològic per Llicà d'Amunt.

\section{VALORACIÓ DE L'ACTIVITAT}

La valoració per part de l'alumnat ha sigut positiva. La creació de la maqueta ,novetat aquest curs, ha sigut molt motivadora. L' utilització de la maqueta com a model per realitzar tant prediccions com explicacions dels fenòmens detectats a la natura ha sigut enriquidora.

La sortida per la vall d'en Tenes és sempre un èxit, una activitat fora del centre on treballen de manera autònoma i poden relacionar-se de forma més espontània.

L'activitat de l'itinerari geològic urbà (també novetat aquest curs) també ha sigut ben rebuda per l'alumnat. Amb ell hem incorporat la competència digital fent la seqüència d'activitats més diversa i atraient.

La meva valoració com a docent és també positiva. Hem treballat i avaluat diverses competències, tant les pròpies de l'àmbit cientificotecnològic com altres més transversals (la digital, lingüística). Les novetats introduïdes aquest curs han completat la seqüència didàctica, han servit per detectar errors de comprensió ( sobretot gràcies a l'activitat del itinerari geològic, que és una activitat d'aplicació i/o interpretació) i per incentivar la creativitat i l'ús de les TIC. També s'ha incidit de forma més directa en l'estudi i coneixement del seu poble i el seu entorn proper.

\section{REFERÈNCIES}

SANMARTÍ, N., BURGOA, B. I NUÑO, T. (2011). Por qué el alumnado tiene dificultad para utilizar sus conocimientos científicos escolares en situaciones cotidianas?. Alambique, 67, 62-69.

JUAN JOSÉ VERGARA RAMÍREZ .Aprendo porque quiero. El Aprendizaje Basado en Proyectos $(\mathrm{ABP})$, paso a paso. Editorial: Grupo SM, colección innovación educativa. 